\title{
Qual passado escolher? Uma discussão sobre o negacionismo histórico e o pluralismo historiográfico ${ }^{1}$
}

Which Past to Choose? A Discussion on Historical Negationism and Historiographical Pluralism

\author{
Arthur Lima de Avila*
}

\section{Resumo}

O objetivo do artigo é apresentar a noção de pluralismo historiográfico como um necessário contraponto teórico $\mathrm{e}$ político ao negacionismo histórico contemporâneo. Nesse sentido, o texto argumenta que, atualmente, as estratégias negacionistas baseiam-se menos na falsificação empírica estrita do que em representações omitidas. Sendo assim, o artigo brevemente analisa um exemplo de negacionismo, oferecido pela empresa Brasil Paralelo, para, num segundo momento, introduzir a definição de pluralismo historiográfico, defendendo sua importância para o combate efetivo do fenômeno negacionista.

Palavras-chave: Negacionismo histórico; Pluralismo historiográfico; Brasil Paralelo.

\begin{abstract}
The article presents the notion of historiographical pluralism as a much-needed theoretical and political counterpoint to contemporary historical negationism, arguing that in our current age, negationist strategies are less based on outright empirical falsifications than in omitted representations. Thus, the article briefly analyzes an example of negationism, produced by the company Brasil Paralelo, to then introduce the definition of historiographical pluralism, defending its importance for the effective fight against the negationist phenomenon.

Keywords: Historical negationism; Historiographical pluralism; Brasil Paralelo.
\end{abstract}

\footnotetext{
* Universidade Federal do Rio Grande do Sul (UFRGS), Porto Alegre, RS, Brasil. arthurlavila@gmail. com <https://orcid.org/0000-0002-7392-8593>
} 
But to choose, with open eyes - even if it is in the dark! - willingly to bind oneself to that tomorrow which does not yet exist, but which is brought into being by the choice itself: that is perhaps the most difficult thing I've ever done in my life. Perhaps this is freedom (Brink, 1991, p. 507).**

Santificaron el odio con oficios solemnes en una lengua de eruditos (Ospina, 2005, p. 39).

O negacionismo está na moda - tão na moda que agora temos até chefes de Estado a seu serviço. Não nos foram oferecidos poucos espetáculos degradantes por Jair Bolsonaro, Donald Trump e Boris Johnson, para citarmos só três, ao longo da pandemia da COVID-19. Ancorados em uma ampla rede de desinformações, todos se esforçaram ao máximo para negar tanto o impacto destruidor do novo coronavírus quanto as medidas profiláticas contra ele. Conhecemos o resultado: só no Brasil, o número de mortos ultrapassou as centenas de milhares sem que nenhum deles tenha merecido maior consideração do presidente além de um (miserável) “e daí?". O negacionismo transformado em política pública: nada surpreendente para o governo de um admirador de torturadores e dedicado à disseminação de falsidades. No entanto, sem um trabalho prévio de normalização dos discursos e das posturas negacionistas, o mainstreaming, estudado por Aurelien Mondon e Aaron Winter (2020), talvez seu sucesso fosse menor. Os "mercadores da dúvida” (Oreskes; Conway, 2010) das últimas décadas cumpriram bem seu propósito ao ajudar na materialização de uma conjuntura de deslegitimação, às vezes indireta, do conhecimento científico, de ataques às universidades e de promoção de um "populismo obscurantista" (Grüner, 2002, p. 60) que iguala disparates a interpretações fundamentadas.

Não tem sido diferente com as Humanidades, com a historiografia em particular. Ainda que o negacionismo histórico não seja uma novidade, ele deixou de estar circunscrito a grupelhos extremistas, sobretudo de negadores

** "Mas escolher de olhos abertos - mesmo que seja no escuro - disposto a prender a si mesmo àquele amanhã que ainda não existe, mas que é trazido à existência pela própria escolha: essa talvez seja a coisa mais difícil que já fiz em toda minha vida. Talvez isso seja liberdade." (traduzimos). 
da Shoah, e tornou-se presença recorrente no debate público (Valencia-García, 2020). ${ }^{2}$ Da romantização do colonialismo à minimização da escravidão no Ocidente, passando pela reabilitação de regimes autoritários diversos, pouco foi intocado por essas operações de normalização do negacionismo, inclusive no Brasil. Em maio de 2019, por exemplo, no plenário do Congresso, um político (príncipe herdeiro de um império defunto) atribuiu a escravização de seres humanos a uma elusiva "natureza humana" e, no aniversário da Abolição, amainou seu impacto para a história nacional - no que foi, claro, prontamente aplaudido por colegas direitistas (uma chegou a falar na necessidade de "recuperação" dos valores cristãos do Império...). As declarações não passaram incólumes, certamente: foram rebatidas pelos manifestantes presentes na sessão e por outros deputados e deputadas. ${ }^{3}$ Contudo, apesar da resposta imediata a elas, as afirmações não deixam de evidenciar a nova "respeitabilidade" pública adquirida por estas (im)posturas.

Evidentemente, esse êxito foi parcialmente possibilitado pela enorme mudança que temos vivido desde, pelo menos, 2015, quando a chamada "Nova Direita" tomou as ruas com sua combinação, no entendimento preciso de Tales Ab'Sáber (2018), de liberalismo econômico, nacionalismo paranoide e conservadorismo autoritário. A eleição de um governo abertamente anticiência e dedicado a destruir as suas condições de produção no país, comportamento exacerbado pela epidemia recente, tornou a situação ainda mais dramática. Não é de se estranhar, nesse contexto, os intensos ataques às universidades e às ciências - as Humanas em especial -, e as absurdas, mas persuasivas para alguns segmentos do público, acusações de "doutrinação" de que são alvos: fazem parte, para usar a hipótese de Alexandre Avelar e Patrícia Valim (2020), da consolidação de uma "governamentalidade negacionista" que visa, em última instância, legitimar a eliminação "real ou simbólica" de setores sociais específicos e destruir o próprio Estado colonizado por essa racionalidade suicidária. Não se pode separar uma coisa da outra.

Neste sentido, a emergência deste fenômeno se insere em um cenário maior de fortalecimento do "ódio à democracia", diagnosticado por Jacques Rancière (2014), com suas tentativas de recusar política e narrativamente o que é devido àqueles que o filósofo francês chamou de "sem-parte" (os sujeitos subalternizados por processos históricos diversos). Entretanto, e essa é uma diferença importante, os negacionismos contemporâneos agem principalmen- 
te através de silêncios, mistificações, ocultamentos e minimizações que se dão no âmbito narrativo, para além do empírico, que visam subtrair determinados passados de nossos presentes, tornando-os insubstanciais, e impor significados unívocos à nossa história - não raro aqueles acalentados pelos setores dominantes. Politicamente, as narrativas negacionistas coadunam-se com as "historiografias de esquecimento" analisadas por Tessa Morris-Suzuki (2005, pp. 8-9), cujo propósito é o de "obliterar a lembrança de certos eventos da consciência pública" e minimizar os entrelaces entre passado e presente e as responsabilidades daí decorrentes - elas desejam expungir, para voltar a Rancière (2014, p. 17), o "excesso" (as demandas democratizantes) representado pelas histórias críticas sobre nosso passado. No caso brasileiro, elas estão vinculadas à estratégia maior da Nova Direita, de não inscrever certos acontecimentos na imaginação coletiva, e às suas tendências, de um lado, apologéticas, em relação à última ditadura civil-militar, e de outro, de minimização, quando não de negação, das sequelas de longa duração de alguns eventos, como, por exemplo, a escravidão e o genocídio indígena (Pereira, 2015).

Frente a isso tudo resta a indagação de como nós, historiadores e historiadoras, poderíamos responder a esse quadro desalentador. Uma das saídas, para além de uma injustificável omissão, é retrocedermos a posições igualmente absolutistas sobre o conhecimento histórico e/ou a importância da historiografia disciplinada, espelhando o discurso e as práticas dos negacionistas e dos seus sequazes. Neste caso, simplesmente replicaríamos seu desprezo pelo pluralismo e agiríamos como inquisidores obcecados com uma identidade disciplinar que não admite ser questionada (LaCapra, 2004, pp. 1-34). No meu entendimento, esta é uma posição indesejável, para não dizer perigosa, porque igualmente autoritária. Se quisermos combater efetivamente os negacionismos, devemos não só alargar nosso leque de aliados e possibilidades de representação do passado, sem obsessões com limites normativos disciplinares, como também defender um pluralismo inapelável que busque "expandir nossa imaginação política" (Laclau, 2000, p. 212), diante do ódio à democracia e da governamentalidade suicidária. Esse será, portanto, o argumento central desse artigo, exposto após um breve exame do negacionismo à brasileira, oferecido pela empresa Brasil Paralelo.

Desta maneira, focar nossas críticas exclusivamente no aspecto empírico é fazer somente metade da tarefa. Certamente, é imprescindível derrotar os 
negacionistas com e pelos arquivos (Ricouer, 2007, p. 156), mas, como nos alertou Michel-Rolph Trouillot (1995, p. 149) há duas décadas, exatidão ou inexatidão documentais não são suficientes para que histórias adquiram estima e legitimidade públicas. Ao escolhermos um pretérito, observou Hayden White (2014, p. 134), escolhemos um presente e usamos aquele para legitimar e dar inteligibilidade a esse. As consequências éticas e políticas destas opções não podem ser secundárias à atestação da veracidade de determinados eventos e processos; ambas precisam ser pensadas concomitantemente. Por esta razão, é igualmente básico chamar à atenção os sentidos para o passado e o presente construídos por estas intervenções, porque é partir deles que poderemos entender as implicações mais amplas das narrativas negacionistas (Trouillot, 1995, p. 149), começando por sua dicotomização extrema da realidade.

Sob esta lógica, tudo que se opõe a elas é denunciado como "ideológico", "político" e pertencendo a uma "conspiração doutrinadora”. É, por exemplo, o que declara um negacionista brasileiro, hoje ocupante de cargo público, quando afirma que "o passado não é um patrimônio dos doutores em história, mas um patrimônio público" (no que, diga-se de passagem, concordo com ele) e um "tesouro" que precisa ser "resgatado" das mãos destes "guardiões": "precisamos quebrar essa história!”, brada ele, para que ela possa ser contada “adequadamente". ${ }^{5}$ A partir desta divisão entre "ladrões" da história e seus libertadores, entende-se melhor o "estilo paranoide" (Hofstadter, 2008) que sustenta essas figurações - é o próprio entusiasmo missionário de que se imbuem que o exige. Tal espírito, por outro lado, impele a submissão das conclusões "históricas” a uma visão ideológica apriorística, levando, assim, à falsificação do pretérito (o pilar básico do projeto negacionista). Há, todavia, que se considerar o que Achille Mbembe (2019, p. 18) chama de "potência do falso", no exame dessas (im)posturas, para entender como funcionam politicamente. É preciso, enfim, tomá-las como uma "pirâmide de certezas" (Mbembe, 2019, p. 17), para usar a expressão do filósofo camaronês, que visam ter um efeito político mais do que cognitivo - como também apontaram Avelar e Valim (2020). Não é coincidência que, no Brasil, esses negacionistas se equiparem a cruzados, ou seja, confiram um (suposto) sentido divinamente sancionado aos seus intuitos de "resgatar" o passado da mão de seus antagonistas ideológicos. 


\section{A REPRESENTAÇÃo OMITIDA}

Quem seriam, então, esses cavaleiros da Cruz tupiniquins? Em nosso país, eles notadamente se reúnem no bem-sucedido empreendimento chamado "Brasil Paralelo", cuja ambição, nas palavras de um de seus fundadores, é a de "expandir a consciência dos brasileiros"6 - os mais céticos diriam que seu objetivo é, na realidade, ser o braço intelectual da Nova Direita, ainda que cinicamente os seus idealizadores se digam "independentes" e "imparciais" (Direito de resposta, 2020). De todo modo, a empresa produz documentários sobre os mais variados temas históricos, além de, mais recentemente, ter voltado suas armas contra a educação pública, editando verdadeiros vitupérios disfarçados de "análise" e, como não podia deixar de ser, contra as supostas conspirações envolvendo a pandemia da COVID-19 (o deslizamento de um negacionismo para outro). Seus colaboradores (que, em sua grande maioria, são todos homens brancos) formam uma verdadeira mélange de profissões, contando com "príncipes herdeiros", especuladores financeiros, jornalistas conservadores, diplomatas, youtubers de direita, influenciadores digitais, (poucos) historiadores profissionais e ideólogos do bolsonarismo em sua versão menos grosseira7, todos devotados à "missão" de mudar a história do Brasil.

Nos seus filmes dedicados aos nossos passados coloniais e imperiais, encontramos alguns velhos tropos decimonónicos, nos quais Lugones puxa Faurisson para dançar uma enviesada valsa freyreana: a conquista providencial e benéfica de um continente virgem, a luta entre a civilização e a natureza selvagem, a fusão das raças em um "povo" mestiço e contente consigo mesmo, o caráter positivo das elites na condução dos destinos do Novo Mundo, o papel civilizador da escravidão, o elogio desmedido aos guerreiros que consolidaram o domínio europeu nos recônditos destas terras, a justificação da guerra justa contra "bárbaros", a organicidade de uma sociedade em que todos sabiam os seus lugares de antemão, a criação de um espírito "nativista" que antecipa a nação e a deferência às hierarquias sociais, surgidas no ambiente colonial e perdidas com a "modernidade". Nesta série de vídeos, sintomaticamente intitulada "Brasil: a Última Cruzada", a identidade do país é vinculada inexoravelmente a um "Ocidente" "cristão" e "livre" sempre açodado por inimigos vários, que precisam ser diligentemente combatidos e derrotados pelos bons homens, sob o risco de perecer. Esta seria a essência nacional a ser recuperada no presente, para que os "brasileiros", definidos arbitrária e limitadamente, 
possam voltar a ter orgulho de seu "patrimônio". Ironicamente, esta alardeada recuperação depende, para sua boa fortuna, de uma série de silêncios, omissões e, obviamente, negações, tanto factuais quanto narrativas.

No que concerne à escravidão, por exemplo, a elipse é a tática privilegiada pelos documentaristas. Suas operações devem, nesse momento, dar-se no nível de uma representação que falseia a história sem, porém, negar os acontecimentos aos quais se refere. Nessas produções, a escravização de milhões de seres humanos não merece mais do que escassos minutos de exposição, num conjunto de seis episódios gratuitos de aproximadamente uma hora e meia cada um. Sim, a voz na tela a chama de "grande chaga brasileira" e "mancha moral" de nossa história, talvez para conferir dramaticidade ao enredo ou demonstrar sensibilidade. No entanto, as suas especificidades são diluídas em referências vazias aos "milênios de história escravista", em ponderações kitsch ${ }^{8}$ acerca deste iluminado "lado da linha do tempo" e em mistificações da sociedade ocidental e do seu "abolicionismo", como se ela tivesse escravizado indivíduos apenas para ter o posterior prazer em libertá-los. ${ }^{9}$

Esta intriga, que trivializa a escravização ${ }^{10}$, exime os luso-brasileiros e demais europeus, tanto na Colônia quanto no Império oligárquico que a seguiu, de responsabilidades mais amplas em relação aos horrores da Passagem do Meio, das senzalas e dos chicotes. Como empresários avant la lettre, estes comerciantes teriam simplesmente aproveitado as oportunidades que lhes foram conferidas pelos africanos; esses, sim, os únicos organizadores desse pérfido comércio. Um dos colaboradores chega, inclusive, a negar qualquer fundamento racial à escravidão nas Américas, enquanto outro usa o exemplo dos (poucos) senhores de escravos negros, para "demonstrar" a ausência deste embasamento étnico. É um artifício nada sutil, obviamente: ao negar que a cor da pele e/ou a origem africana tenham sido condicionantes, no longo prazo, para a escravização de um indivíduo qualquer, nega-se a possibilidade de reconhecimento das desigualdades raciais e sociais advindas desta "coincidência". Similarmente, a "prudência" com que o escravismo foi tratado por nossa elite, que tão só prolongou o sofrimento de milhões de "pessoas-mercadorias" (Mbembe, 2014, p. 89), é alçada à categoria de virtude ("a forma como ela foi superada é motivo de orgulho", diz um historiador paralelo), pois teria "prevenido um banho de sangue" análogo ao da Guerra Civil norte-americana. Nos tristes trópicos, a história se resolve sozinha ou com o auxílio dos poucos aptos 
a fazerem-na. Ao restante, cabe o dúbio privilégio de sofrê-la, até que os cautelosos achem por bem mudar, mas nem tanto, o rumo dos acontecimentos - o "futuro como dádiva", do qual fala Mbembe (2014, p. 259), entregue, na visão do Brasil Paralelo, por generosos senhores. O papel dos sujeitos escravizados na realização de suas próprias histórias, com brevíssimas exceções, nem sequer merece menção; eles são massa inerte, submetida aos rumos de uma história em que figuram enquanto meros objetos.

Com isso, trezentos anos de cativeiro são, por fim, metaforizados como um "pecado" descarnado de processos (e corpos!) históricos concretos - um desacerto "moral" corrigido com a Abolição. Daí em diante, o resto é silêncio, salvo por alguma ou outra história de superação, sempre individual, que provaria que o tão comentado racismo brasileiro não passaria de uma criação ideológica daqueles dedicados à divisão do país em raças e classes. Ora, por esse passe de mágica narrativo, a realidade presente resta naturalizada, e problemas sociais mais amplos, agora desistoricizados, podem ser atribuídos a disposições pessoais ou às características inatas dos grupos subalternizados. Não há nenhum fardo ou ferida histórica a ser nomeado, quanto mais a ser reconhecido e reparado. Esse enredamento, portanto, é menos um negacionismo dos fatos do que um negacionismo de fato; ou, de acordo com a conceitualização de Perry Anderson (2008, p. 108), é menos a suggestio falsi, o embuste deliberado, do que a suppressio veri, "a representação omitida", que engendra versões falseadas através da deleção, da manipulação e da distorção do registro histórico, e não necessariamente da mentira óbvia, embora o limite entre esses processos possa ser tênue.

Esta suppressio veri equivale socialmente àquilo que Ricouer (2007, pp. 82-103) tão aptamente denominou de "memória impedida", cujo objetivo parece ser o de prevenir o trabalho de lembrança que também é um trabalho de luto. As violências inerentes a um sistema escravista, além de suas duradouras consequências para o país, são esvaziadas de qualquer sentido maior. Logo, de pouco adiantam as referências dos entrevistados ao "caráter mestiço" da "civilização brasileira” e os seus elogios à “diluição das fronteiras raciais” (supostamente) acontecida em terras brasílicas. Pelo contrário, no cômputo geral, elas se tornam declarações cínicas, pois o arco narrativo proposto pelo Brasil Paralelo reitera a uma parcela substantiva da população brasileira sua condição de permanentemente "sem-parte" na divisão de nossa história. Sua exclusão é 
o preço que devemos pagar, deduz-se pelas obras da produtora, para que possamos "resgatar" o orgulho nacional. Os laços indeléveis entre a nossa modernidade e o sistema escravista são, nessa abordagem, subtraídos por uma politização do tempo histórico que, se não nega a existência da escravidão em si, a torna insubstancial para o presente e, por conseguinte, apresenta uma narrativa falsa, por causa da elisão do acontecimento que deveria ser seu "referente último” (Ricouer, 2007, p. 190). Isso não é uma simples coincidência ou um erro empírico: é uma intervenção crucial para "deixar um trauma em suspensão", para usarmos os termos de Avelar e Valim (2020), e impedir que um fato possa sequer ser nomeado enquanto tal, tornando-o, se não impensável, ao menos indizível.

No que concerne à última ditadura civil-militar, objeto de sua obra mais conhecida, o documentário "1964, o Brasil entre Armas e Livros" (1964 - O Brasil...), a estratégia da produtora é mais explicitamente negacionista, como demonstram as críticas feitas por uma série de autores (Nicolazzi, 2019a; Nicolazzi, 2019b; Escorel, 2019). Em linhas gerais, o que o Brasil Paralelo nos fornece, sob a forma de um produto tecnicamente muito bem elaborado, é, não obstante algumas reprimendas pontuais ao regime, a normalização do que Ricouer (2007, p. 341) alcunhou de “o injustificável”. Nisso, sabemos, a empresa não está sozinha, já que a reabilitação dos generais e dos seus asseclas, assim como a negação de seus crimes, tem encontrado espaço em diversos segmentos da sociedade brasileira. Lembremos, seguindo Pereira (2015) e Ab’Sáber (2018), das reações virulentas contra a Comissão da Verdade, dos cartazes em homenagem a torturadores nas manifestações de 2015 e 2016 e dos pedidos de "intervenção militar" ouvidos em profusão nos últimos anos. Neste sentido, as narrativas do Brasil Paralelo cumprem o vaticínio feito por Paulo Arantes há alguns anos: "por essa via, a paranoia exterminacionista da Ditadura ainda será reinterpretada como o efeito do pânico preventivo disparado pela marcha apavorante de um gulag vindo em nossa direção" (Arantes, 2014, pp. 285-286).

E é justamente isso que acontece no filme. Em "1964, o Brasil entre Armas e Livros", o sentido histórico atribuído à derrubada de João Goulart é, não surpreendentemente, o de "salvação" da nação das garras do bolchevismo insidioso representado pelo presidente e por seus aliados - sentido que se comprova por uma profusão de testemunhos individuais tediosamente perfilados 
na tela. Parte expressiva das entrevistas usadas na produção centra-se em torno de depoimentos de sujeitos que "corroboram" essa tese, baseando-se nas suas memórias individuais dos acontecimentos, sem matizações ou ponderações de quaisquer tipos, como, por exemplo, a apresentação de recordações contrárias, outras interpretações historiográficas ou provas documentais capazes de sustentar a (suposta) explicação causal - o apagamento simbólico das vítimas na obra repete a sua eliminação física num paralelismo revelador. $\mathrm{O}$ resultado, observa o cineasta Eduardo Escorel (2019), é “uma mixórdia resultante da junção de um conjunto heterogêneo de recursos de linguagem gastos, a serviço da tentativa de demonstrar uma tese enunciada no final do vídeo". É nesse sentido que se pode falar, como eu o fiz na introdução deste texto, que a história é irremediavelmente submetida à política, no pior tipo de sujeição, no documentário. ${ }^{11}$

Pela ótica da película, temos uma inversão: a democracia seria, em realidade, uma ditadura mascarada, controlada por comunistas, e a ditadura seria uma democracia, porque teria "libertado" o país de seus inimigos e controlado a "ameaça vermelha". ${ }^{12}$ De uma quartelada antidemocrática, o golpe de 1964 passa a ser um acontecimento redentor (a repetição do linguajar dos golpistas é, vê-se, recorrente no filme) e providencial. Quem se opôs à derrubada de João Goulart é reduzido à categoria (fetiche para os neoautoritários) de "corrupto". O documentário figura o período entre 1964 e 1968 como um episódio razoavelmente democrático, com especial atenção (e carinho!) à eleição indireta de Castelo Branco. Apesar de ter sido possível somente pela derrocada ilegal de Jango, ela é transformada em um episódio de congraçamento democrático e de "renascimento" do país. As breves admoestações contra os governos militares só são feitas para o pós-AI-5, e apenas por poucos entrevistados - o que pode até aliviar a consciência dos realizadores do filme, mas não muda seu resultado final. Toda a máquina de sevícias e torturas instaurada pelo regime, com a anuência de seus próceres ${ }^{13}$, desaparece de vista, com uma ou outra exceção, pontual e rápida (o caso Herzog, por exemplo). Da mesma maneira, a luta armada é exagerada em seu tamanho e escopo de atuação e toda a oposição ao arbítrio é reduzida a ela, o que, evidentemente, justificaria a resposta dos militares; os crimes cometidos, fartamente documentados, contra cidadãos e cidadãs que nada tinham a ver com os grupos guerrilheiros, são, por esse reductio ad absurdum, tanto legitimados quanto negados, numa espécie de 
reivindicação pela negação. Estamos frente a uma falsificação histórica gritante, que omite que o terror de Estado e o seu "poder torturador", para parafrasear Pilar Calveiro (2013), fundamentais ao funcionamento do regime que querem reabilitar como "democrático". ${ }^{14}$

Daí até o fim do longa-metragem, temos só apologias para a violência ditatorial, algumas recriminações ao modelo econômico do regime, considerado demasiadamente estatizante e, como era de se esperar, a acusação de que as lideranças de esquerda de então seriam todas, sem exceção, compostas por "bandidos" e "terroristas" - a imagem da Presidenta Dilma Rousseff emerge, nada inocentemente, na tela nesse momento. As frases finais, que reproduzo ipsis litteris aqui, transparecem o que os autores do documentário pensam sobre a democracia que se seguiu à noite de vinte e um anos:

A revolução se transmutou das armas para os livros. Transformou um lado da guerra em mártir, fez da história propaganda, panfletou nas escolas, na mídia, nas universidades. Formou a nova geração brasileira. Esta geração foi trabalhar nos meios de comunicação, nas editoras, na educação do Brasil. A hegemonia quase apagou o passado e perpetuou uma narrativa. Um lado da guerra foi herói e o outro, opressor. O que fizeram os heróis?

O recado, embora confuso, está dado: todas as narrativas críticas à ditadura são, aos olhos dos documentaristas, frutos desta "transmutação" dos "revolucionários" em "mártires", e, por isso, mentirosas e ilegítimas, ao contrário daquela que nos é oferecida pela empresa. A extrema-direita encontra seu novo mito fundador, que vem para substituir os da Nova República, em uma "ficcionalização radical da história, um sistema fabular fantástico [...] que escolhe os mínimos pontos de contato com fatos reais, os isola e hiper-investe para fazer emergir o conto político fantástico interessado como a verdade do processo histórico" (Ab’Sáber, 2018, pp. 80-81). ${ }^{15}$

Não temos, nessa operação, somente uma tentativa de recuperar a velha teoria dos dois demônios, mas o intento claro de fazer de 1964 um contraponto positivo em contraste com a "corrupção democrática" pós-1988. ${ }^{16}$ Em uma conjuntura de vitória eleitoral do bolsonarismo e de crise da democracia liberal, tais figurações visam corroborar a virada autoritária em curso, a perseguição da "esquerda", identificada com tudo que não esteja alinhado automaticamente à "nova política", e, o que é mais grave, visam deslegitimar a ordem consti- 
tucional vigente como inerentemente falha, decaída e subversiva, pois elaborada pelos perdedores de 1964 - “uma farsa!”, vocifera um colaborador, não sem uma dose de mal disfarçado ódio. Os gestos de reivindicação, explícita ou não, dos torturadores, conforme escreveu Vladimir Safatle (2019), são sintomáticos desta perspectiva: o "Ustra vive!", replicado à exaustão nos últimos anos, é tanto o signo de uma rejeição à democracia quanto uma celebração da violência e do arbítrio mais brutais. O torturador, aliás, é tratado pelos documentaristas, em um dos trechos mais atrevidamente negacionistas do filme, como um simples "perseguido" pelos desejos de vendeta destes subversivos ressentidos pela derrota. O coronel teria sido acossado por "não se curvar" aos esquerdistas e aos seus aliados. Perversamente, a mensagem final da obra pode ser entendida como um lamento pelo que os militares não fizeram, isto é, por não terem executado e violentado ainda mais, para que a "esquerda" nunca mais tivesse a chance de "submeter" o país aos seus projetos ideológicos e políticos. Há, deste modo, um continuum entre as figurações do Brasil Paralelo e o negacionismo inequívoco do atual Presidente da República, para quem a ditadura não foi suficientemente ditadura ("temos que fazer o que os militares não fizeram", bradou ele um dia): os silenciamentos da tortura e das mortes pela empresa funcionam como a reinvindicação pela negação, que autoriza "cientificamente" as afrontas de Bolsonaro contra a democracia. Um não tem efetividade pública sem o outro, pois, na frase certeira de Ricouer (2007, p. 98), "até o tirano precisa de um retórico, um sofista, para transformar em discurso sua empreitada de intimidação e sedução". Sob essa perspectiva, o Brasil Paralelo exculpa, não explica. Se há um método que distorce a história brasileira, para voltar ao mote do grupo, é, ironicamente, o seu próprio. E, se há uma narrativa que rouba de nosso povo os "tesouros" de seu passado, não é outra senão a desses "envenenadores que querem se passar por médicos” (Nietzsche, 2005, p. 89).

\section{O MUNDO EM FEIXES}

Tendo visto alguns dos elementos fundamentais deste negacionismo à brasileira, elaborado por propostas como a do Brasil Paralelo, ainda resta a questão sobre o que podemos (devemos?) fazer diante dele. Fingir que não importa não é uma opção, dado o sucesso de público que estes empreendimentos alcançaram. ${ }^{17}$ De outra forma, chamar seus autores ao debate em nossos 
fóruns, como se possuíssem legitimidade intelectual semelhante à da boa historiografia, também não me parece uma escolha sensata. Somos seus inimigos, não cansam de repetir. Como navegar por este cipoal todo, ainda mais em um contexto político de continuada degradação da democracia? Como criticar falsificações de vários tipos, sem, entretanto, retroceder a um "realismo ingênuo" (Ricouer, 2007, p. 270), igualmente inadequado para dar conta de diversos eventos e processos pretéritos? Estas são, afinal de contas, interrogações que já foram feitas em outros pontos no tempo, sendo, nos lembra Patrick Finney (1998), tanto políticas quanto historiográficas. Cabe a nós buscar alternativas aos tipos de fechamento da história que os negacionistas propõem e insistir na defesa de um pluralismo historiográfico impenitente. Definamos, então, os termos desse embate.

Em primeiro lugar, a noção de pluralismo historiográfico parte da premissa, poeticamente expressada por Kerwin Klein (1997, p. 5), de que "as histórias que contamos são os mundos em que vivemos". Qualquer tentativa de cercear esta multiplicidade equivale a uma clausura arbitrária dos sentidos que queremos dar às nossas vidas e dos horizontes de expectativa daí imaginados. Um dos efeitos mais cruéis dos negacionismos é a recusa destas possibilidades ou, dito diferentemente, a fixação de significados absolutos, baseados em falsificações ou exclusões históricas, para nossos mundos; no caso do Brasil Paralelo, amparados em justificativas inaceitáveis do terror de Estado, na lógica de inimizade perene, na deterioração da democracia como valor compartilhado, em uma universalidade falsa, porque respaldada por uma metonímia espúria e na supressão do reconhecimento de feridas históricas coletivas.

Contra isso, o pluralismo historiográfico admite que existe "um número de relatos igualmente plausíveis sobre o passado ou um número de diferentes, mas igualmente significativas construções do passado" (White, 2010, p. 226) que chamamos de "história". Isto - e ressalto a importância desse ponto -, não quer dizer que o "pretérito nunca tenha existido, que não possamos ter informações mais ou menos precisas sobre ele e que não possamos convertê-las em conhecimento" (White, 1999, p. 2) com a aplicação dos vários métodos que pensamos ser adequados a esta tarefa, porque o podemos e o fazemos. Uma defesa do pluralismo historiográfico não é, de forma alguma, a ratificação da negação, da mentira, da falsidade ou, para usar o linguajar contemporâneo, de fake news diversas, como se fossem equivalentes ao labor historiográfico res- 
ponsável. Logo, o pluralismo não leva à aceitação acrítica de qualquer interpretação ou à suspensão de julgamentos acerca da "responsabilidade perante as regras da evidência" ou a "consistência lógica" (White, 1994, p. 114) de uma representação. Para criticar falsificações históricas ou historiografias incompetentes (Cézar, 2012, p. 36), não precisamos retroceder a um "positivismo redivivo" (LaCapra, 2000, p. 206), que reduz qualquer querela à questão de uma verdade factual strictu sensu. Estas não são nossas duas opções, felizmente.

Mas, voltemos a uma outra questão de igual magnitude: por que, não obstante a sua manifesta falsidade ou implausibilidade, os negacionismos e demais historiografias do esquecimento acalentam uma parte expressiva da audiência? Para além de um nacionalismo autoritário e repressivo, a atração do Brasil Paralelo parece residir em seus enredos heroicos, bastante encantadores para aqueles que talvez se sintam ameaçados pelo avanço do que chamam de "minorias" e que sonham com a restauração de velhas hierarquias sociais, mesmo que elas nunca tenham realmente desaparecido - o ressentimento nascido da percepção de que a sua dominação está retraindo (Brown, 2019, pp. 174-175). O próprio título “A Última Cruzada” é um indício disto. Usando as análises de Chantal Mouffe (2009, pp. 102-103), pode-se inferir que elas oferecem uma maneira de se "mobilizar paixões e criar formas coletivas de identificação", em um mundo o qual parte desta audiência não reconhece mais como seu, ainda que articuladas em torno de polaridades incomensuráveis e de um antagonismo perpétuo que só se encerrará com a eliminação total do adversário. Não deixa de ser irônico que interpretações opostas aos "identitarismos" das "minorias" sejam, elas próprias, identitárias in extremis, malgrado a sua pretensão de "universalidade", porque imaginadas como um consolo para uma população branca e masculina ${ }^{18}$ que se sente ameaçada pelo avanço dos sem-parte e do seu excesso democratizante. Nas palavras de dois autores, Laclau (2014, pp. 139-180) e Roland Barthes (2005, p. 83), elas constroem um "povo" por meio de uma gramática que toma uma parte pelo todo e que não admite contestação, precisamente por prescindir de qualquer visão plural da história. Aliás, esta metonímia é a base pela qual podem rejeitar o pluralismo historiográfico (e, por extensão, político): tudo que não se insere em sua imaginação sobre o "povo brasileiro" é descartado de antemão como "subversivo", "ideológico" ou, em situações extremas, inumano. ${ }^{19}$ Esta operação, se continuarmos seguindo os indicativos de Laclau (2014, pp. 1-9), visa 
“congelar" uma metonímia em uma metáfora permanente e, com isso, se transformar em uma universalidade vazia, pois fundamentada em uma particularidade que não se reconhece enquanto tal. Neste caso, o que é uma "contiguidade contingente" (Laclau, 2014, pp. 63-64), resultante das escolhas narrativas e das opções políticas dos donos e colaboradores da empresa, torna-se uma "essência" encontrada na história, utilizada para demarcar quem é "amigo" ou "inimigo - um gesto capital para os projetos de hegemonia da Nova Direita.

Isso, claro, não é gratuito. Voltando às considerações de Avelar e Valim (2020), pode-se dizer que, ao criar uma comunidade de semelhantes restrita no passado, o negacionismo chancela a produção de uma no presente, servindo para o congelamento de "políticas de inimizade" (Mbembe, 2017) e das linhas de separação que advêm delas. Os que têm história estão devidamente protegidos pelos mecanismos da Lei (ou são eles próprios a Lei), enquanto os que se encontram fora de suas demarcações são transmutados em sujeitos dispensáveis, verdadeiros mortos-vivos (Mbembe, 2017, pp. 107-152). O negacionismo é, então, um elemento central deste ódio à democracia e das necropolíticas que lhe são inerentes. Ao legitimar a brutalização dos sujeitos pretéritos, seja pela recusa de sua facticidade, seja pela reinvindicação da violência como necessária à preservação da segurança da comunidade de semelhantes, ele avaliza essa mesma brutalização no presente. $\mathrm{O}$ apagamento de certas histórias torna-se uma maneira de se organizar a pólis e de se eliminar o excesso que coloca em risco o essencialismo necessário a esses projetos de poder. No horizonte inaugurado por este "princípio de destruição" (Mbembe, 2017, p. 154), a pluralidade das histórias, dos passados e das experiências humanas precisa ser destruída para que um "regime de clausura" (Mbembe, 2019, p. 156) venha a ser instituído.

A defesa do pluralismo, por esse prisma, reinstaura nossa "condição comum”, na expressão de Mbembe (2017, p. 249), ajudando-nos a pensar em "todos os feixes do mundo" para, quem sabe, desmontarmos essas políticas de inimizade nefastas. Todavia, insistir nela pode parecer, a pessoas mais afeitas às ortodoxias disciplinares, uma concessão a um relativismo perigoso. Carlo Ginzburg (2006) e Roger Chartier (2002), para ficarmos apenas com dois luminares, nos avisaram deste risco, quando dos "debates" acerca da virada linguística nas décadas de 1980 e 1990. No seu entendimento, uma vez que aceitássemos a "relatividade inexpugnável de qualquer representação histórica" 
(White, 1999, p. 27), estaríamos automaticamente legitimando as mentiras negacionistas. Esses alertas foram replicados à exaustão por uma série de outros autores e autoras, que continuamente nos avisaram que a ameaça relativista ("pós-moderna") era tão ou mais perigosa que a do negacionismo (Lipstadt, 1994; Friedlander, 2008). Como era de se esperar, eles voltaram à tona nos últimos anos, frente à vaga negacionista (Kleinberg, 2019). Todavia, é necessário recordarmos que negacionistas, soft ou não, rejeitam o relativismo de que são acusados; pelo contrário, suas concepções de "verdade histórica" são calcadas em um anseio objetivista que não é de todo diferente daquele da ortodoxia disciplinar, isto é, não admitem que possam existir inúmeras representações dos fenômenos pretéritos, todas igualmente plausíveis (se, repitamos, cumpridos os protocolos de respeito às evidências e à responsabilidade teórica-conceitual).

Os esforços do Brasil Paralelo em se apresentar como a única fonte de autoridade sobre a história nacional são uma boa ilustração disto. Ali, não existe qualquer relativismo, moderado ou radical. Por isso, não me parece uma boa estratégia mirarmos em um objetivo que nem de longe é o deles. Ademais, as consequências podem ser ainda piores, pois simplesmente contraporíamos um desejo absolutista a outro e perderíamos de vista a ideia de que o passado, como nos disse Benjamin na meia-noite do século XX, é (ou deveria ser) aberto. Neste sentido, é preciso insistir na indeterminação última do pretérito, ou seja, nos "passados possíveis" que permitem nossos "possíveis passados”, na acepção de Kleinberg (2017, pp. 137-138), e que postulam uma miríade de sentidos para nossas histórias e existências:

Nosso conhecimento sobre o passado é condicionado pelo que se apresenta a nós tanto nos termos de seus restos quanto de nossa recepção. Os limites do que estamos dispostos a aceitar como "passados possíveis" condiciona o que estamos dispostos a aceitar como "possíveis passados". Aquilo que jaz além deste reino nos aparece como simplesmente impossível, como um fantasma [...]. O passado latente não é o impossível; ele foi possível e ele aconteceu, ainda que possa ter se tornado inconcebível ou inimaginável e, assim, exilado para além do que agora parece possível.

O que está "exilado no reino além do possível" em um dado momento pode regressar para assombrar os vivos. Se o que está latente no passado des- 
cerra novas possibilidades no presente, como aponta Kleinberg (2017, p. 138), as narrativas do Brasil Paralelo, as historiografias do esquecimento aqui criticadas também podem ser compreendidas como um enorme esforço de repressão destas mesmas possibilidades na atualidade. $\mathrm{O}$ negacionismo, com suas tentativas de não-inscrição de certos passados em nossa vida pública, limita e cerceia o que podemos considerar como nossos possíveis passados, retirando-os de cena e empobrecendo nossa imaginação histórica. Essa estratégia, para citar LaCapra (2018, p. 39), fecha outros futuros realizáveis pelos sujeitos históricos, mas que não estão necessariamente à sua vista imediata. A obsessão da empresa em criar uma "identidade positiva" para o país, assentada numa suspensão de traumas que dá guarida à nossa saída contemporânea da democracia, nos fornece "somente um sentido ilusório e não permitem a emergência de futuros aceitáveis" (LaCapra, 1994, p. 66), pois não os protege "das faltas do passado" (Ricoeur, 2007, p. 462), privando a opinião pública do dissenso básico para a convivência democrática. Através desse gesto, que, com o perdão do trocadilho, não nega sua relação com períodos autoritários anteriores, ela encerra tanto o passado quanto o presente em si mesmos, prevenindo a busca por outras respostas para as tribulações atuais e sedimentando a "utopia autoritária" que, de acordo com Avelar e Valim (2020), é o corolário da governamentalidade suicidária. Por esse motivo, a disputa em torno do problema negacionista também é um confronto sobre o que está por vir: que tipo de futuro podemos erigir se o basearmos na trivialização da tortura, no aplauso ao arbítrio, na normalização do terror de Estado e na consignação de uma multidão ao status de não-cidadãos, cujos sofrimentos e esperanças não têm valor?

Finalmente, o pluralismo, como definido aqui, é uma postura que almeja, na metáfora de Imré Kertész (2004, p. 41), “tornar o mundo habitável”. Mais do que isso, ele leva a sério a proposição de que não existem histórias absolutas, e é bom que não existam, e que a democracia depende, em larga medida, da proliferação de um sentido agônico de história - para voltarmos a Mouffe (2009, pp. 80-107) -, o qual reconhece que qualquer cesura categórica do passado é indesejável. Isto, sem dúvida, é uma concessão a um relativismo que não teme dizer seu nome. É verdade que ela não é uma salvaguarda permanente contra negacionismos e leituras fascistas e/ou autoritárias do passado e do presente (talvez porque essa salvaguarda simplesmente não exista). Esse é o risco da vida na história. Mas, segundo Finney (1998, p. 368), é melhor levar 
essa luta adiante em condições em que a relatividade e a contingência da história são reconhecidas, ajudando os cidadãos e as cidadãs a escolherem seus passados com os olhos abertos, do que em circunstâncias em que elas são recusadas. Não é coincidência, logo, que o Brasil Paralelo invista tão pesadamente contra as histórias realmente democratizantes que circulam em nosso país, tentando se apresentar como o portador de uma verdade absoluta que não admite quaisquer contestações: aceitá-las seria aceitar uma democracia verdadeiramente plural, uma em que os "excessos" não seriam domados e/ou recusados, a qual seria antagônica ao espírito mesmo da "nova ordem" preconizada pelo bolsonarismo e sustentada pelo negacionismo "imparcial" da empresa.

\section{Pós-ESCRITO}

É evidente que nada do que foi escrito nessas páginas serve como garantia de sucesso nessa luta inglória. Não mesmo. A historiografia sozinha não pode fazer muita coisa e certamente não substitui, por si só, as lutas cotidianas por verdade, compaixão e justiça. Pesquisa histórica alguma pode, e aqui repito Trouillot (1995, pp. 150), deter a sedução do autoritarismo. O que podemos fazer, contudo, é continuamente combater pelo direito à história (Araújo, 2017, pp. 191-216), subtraído de uma parcela significativa dos indivíduos pelos negacionistas, oferecendo não somente leituras plausíveis do tempo antes de agora, mas também "uma visão do futuro que nos dê esperança, ao invés de permanecer somente no registro da denúncia" (Mouffe, 2018, p. 76). Este combate é uma das principais batalhas de nossos dias. E não podemos, mesmo que quiséssemos, escapar dela, porque tudo aquilo que não fizermos, outros farão e, nos avisa Trouillot (1995, p. 153), enquanto uns debatem sobre o que a história foi ou é, alguns a tomam nas mãos. Que, diante do descalabro do mundo e da santificação do ódio na língua de eruditos, sejamos nós a fazê-lo. Caso nos recusemos, poderá ser tarde demais.

\section{REFERÊNCIAS}

99. MEMORANDUM FROM Director of Central Intelligence Colby to Secretary of State Kissinger. 11 abr. 1974. Disponível em: https://history.state.gov/historicaldocuments/frus1969-76ve11p2/d99?platform=hootsuite. Acesso em: 1 nov. 2020. 
AB'SÁBER, Tales. Michel Temer e o Fascismo Comum. São Paulo: Hedra, 2018.

ANDERSON, Perry. Sobre el entramado: dos clases de hundimiento. In: FRIEDLANDER, Saul (Org.). En Torno de los Límites de la Representación: el nazismo y la solución final. Quilmes: Universidad Nacional de Quilmes Editorial, 2008. pp. 93-108.

ARANTES, Paulo. O Novo Tempo do Mundo: e outros estudos sobre a Era da emergência. São Paulo: Boitempo, 2014.

ARAÚJO, Valdei Lopes de. O Direito à História: o(a) historiador(a) como curador(a) de uma experiência histórica socialmente distribuída. In: GUIMARÃES, Géssica; BRUNO, Leonardo; OLIVEIRA, Rodrigo Perez de. Conversas sobre o Brasil: ensaios de crítica histórica. Rio de Janeiro: Autografia, 2017. pp. 191-216.

BARTHES, Roland. Inéditos. Vol. 4 - Política. São Paulo: Martins Fontes, 2005.

BAUER, Caroline Silveira; NICOLAZZI, Fernando Felizardo. O historiador e o falsário: usos públicos do passado e alguns marcos da cultura histórica contemporânea. Varia Historia, Belo Horizonte, v. 32, n. 60, pp. 807-835, 2016.

BRASIL PARALELO: em entrevista exclusiva, conheça a origem dos documentários que fazem sucesso na Internet. 19 jul. 2018. Disponível em: https://www.boletimdaliberdade.com.br/2018/07/19/brasil-paralelo-em-entrevista-exclusiva-conheca-a-origem-dos-documentarios-que-fazem-sucesso-na-internet/. Acesso em: 1 nov. 2020.

1964 - O BRASIL entre armas e livros. (127 min. 19 seg.); son.; color. Disponível em: https://www.youtube.com/watch?v=yTenWQHRPIg. Acesso em: 1 nov. 2020.

BRINK, André P. Chain of Voices. New York: Penguin, 1991.

BROWN, Wendy. In the Ruins of Neoliberalism: the Rise of Antidemocratic Politics in The West. New York: Columbia University Press, 2019.

CALVEIRO, Pilar. Poder e Desaparecimento: os campos de concentração na Argentina. São Paulo: Boitempo, 2013.

CÂMARA DOS DEPUTADOS: Sessão solene em homenagem aos 131 anos da assinatura da Lei Áurea é marcada por protestos. 14 mai. 2019 (20 min. 29 seg.); áudio. Disponível em: https://www.camara.leg.br/radio/radioagencia/557513-sessao-solene-em-homenagem-aos-131-anos-da-assinatura-da-lei-aurea-e-marcada-por-protestos/. Acesso em: 1 nov. 2020.

CAPÍTULO 2 - A Vila Rica | Brasil - A Última Cruzada. (69 min. 28 seg.); son.; color. Disponível em: https://www.youtube.com/watch?v=svViHH8IBVg. Acesso em: 1 nov. 2020.

CÉZAR, Temístocles. Tempo presente e usos do passado. In: VARELLA, Flávia et al. (Org.). Tempo presente \& usos do passado. Rio de Janeiro: Editora FGV, 2012. CHARTIER, Roger. À Beira da Falésia. Porto Alegre: EdUFRGS, 2002. 
O DIA DEPOIS da Eleição | Episódio 1: O que sobrou do Brasil? pt. 1. 19 jun. 2018; (29 min. 46 seg.); son.; color. Disponível em: https://www.youtube.com/ watch?v=RvtTyZ4-N4w. Acesso em: 1 nov. 2020.

DIREITO DE RESPOSTA da Brasil Paralelo. 21 jul. 2020. Disponível em: https://diplomatique.org.br/direito-de-resposta-da-brasil-paralelo/. Acesso em 1 nov. 2020. COMISSÃO DE FAMILIARES de Mortos e Desaparecidos Políticos. Dossiê Ditadura: mortos e desaparecidos políticos no Brasil (1964-1985). São Paulo: Imprensa Oficial, 2009.

ESCOREL, Eduardo. A direita na tela: Notas sobre um panfleto audiovisual que revê 1964. 2019. Disponível em: https://piaui.folha.uol.com.br/materia/direita-na-tela/. Acesso em: 1 nov. 2020.

FINNEY, Patrick. Ethics, Historical Relativism and Holocaust Denial. Rethinking History, Taylor \& Francis, vol. 2, n. 3, pp. 359-369, 1998.

FRIEDLANDER, Saul. Introducción. In: FRIEDLANDER, Saul (Org.). En Torno de los Límites de la Representación: el nazismo y la solución final. Quilmes: Universidad Nacional de Quilmes Editorial, 2008. pp. 21-46.

GINZBURG, Carlo. O extermínio dos judeus e o princípio da realidade. In: MALERBA, Jurandir (Org.). A História Escrita: teoria e história da historiografia. São Paulo: Contexto, 2006. pp. 211-232.

GRÜNER, Eduardo. El Fin de las Pequeñas Historias. Buenos Aires: Paidós, 2002.

HOFSTADTER, Richard. The Paranoid Style in American Politics and Other Essays.

New York: Vintage Books, 2008.

KERTÉSZ, Imre. A Língua Exilada. Tradução: Paulo Schiller. São Paulo: Companhia das Letras, 2004.

KLEIN, Kerwin Lee. Frontiers of Historical Imagination: Narrating the European Conquest of Native America, 1890-1990. Berkeley: University of California Press, 1997. KLEINBERG, Ethan. Haunting History: For a Deconstructive Approach to the Past. Stanford: Stanford University Press, 2017.

KLEINBERG, Ethan. Pandering to the timid: the truth about post truth. Wild On Collective, 2019. Disponível em: https://www.academia.edu/38283250/Pandering to_the_Timid_the_truth_about_post-truth. Acesso em: 1 nov. 2020.

LACLAU, Ernesto. Structure, history and the political. In: LACLAU, Ernesto; BUTLER, Judith; ZIZEK, Slavoj. Contingency, Hegemony, Universality: Contemporary Dialogues on the Left. London: Verso Books, 2000. pp. 182-212.

LACLAU, Ernesto. The Rhetorical Foundations of Society. London: Verso Books, 2014. LACAPRA, Dominick. Representing the Holocaust: History, Theory, Trauma. Ithaca: Cornell University Press, 1994.

LACAPRA, Dominick. History and Reading. Ithaca: Cornell Unniversity Press, 2000.

LACAPRA, Dominick. Understanding Others: Peoples, Animals, Pasts. Ithaca: Cornell University Press, 2018. 
LIPSTADT, Deborah. Denying the Holocaust: the Growing Assault on Truth and Memory. London: Plume, 1994.

MBEMBE, Achille. Crítica da Razão Negra. Lisboa: Antígona, 2014.

MBEMBE, Achille. Políticas de Inimizade. Lisboa: Antígona: 2017.

MBEMBE, Achille. Sair da Grande Noite: Ensaio sobre a África descolonizada. Petrópolis: Vozes, 2019.

O MÉTODO QUE... O método que distorce a história do Brasil | Rafael Nogueira. (49 seg.); son.; color. Disponível em: https://www.youtube.com/watch?v=9AusF45Sjr0. Acesso em: 1 nov. 2021.

MONDON, Aurelien; WINTER, Aaron. Reactionary Democracy: How Racism and the Populist Far-Right Became Mainstream. London: Verso Books, 2020.

MORRIS-SUZUKI, Tessa. The Past Within Us: Media, Memory, History. London: Verso Books, 2005.

MOUFFE, Chantal. The Democratic Paradox. London: Verso Books, 2009.

MOUFFE, Chantal. For a Left Populism. London: Verso Books, 2018.

NICOLAZZI, Fernando. O Brasil Paralelo entre o passado histórico e a picanha de papelão. 7 abr. 2019a. Disponível em: https://www.sul21.com.br/ opiniaopublica/2019/04/2019-o-brasil-paralelo-entre-o-passado-historico-e-a-picanha-de-papelao-por-fernando-nicolazzi/. Acesso em: 1 nov. 2020.

NICOLAZZI, Fernando. A história da ditadura contada pelo Brasil Paralelo. 23 mar. 2019b. Disponível em: https://www.sul21.com.br/opiniaopublica/2019/03/a-historia-da-ditadura-contada-pelo-brasil-paralelo-por-fernando-nicolazzi/. Acesso em: 1 nov. 2020.

NIETZSCHE, Friedrich. Escritos sobre História. Tradução de Noeli Correia de Melo Sobrinho. Rio de Janeiro: Editora PUC-Rio; São Paulo: Edições Loyola, 2005.

ORESKES, Naomi; CONWAY, Erik M. Merchants of Doubt: How a Handful of Scientists Obscured the Truth on Issues from Tobacco Smoke to Global Warming. New York: Bloomsbury Press, 2010.

OSPINA, William. Ursúa. Bogotá: Alfaguara, 2005.

PEREIRA, Mateus Henrique de Faria. Nova direita? Guerras de memória em tempos de Comissão da Verdade (2012-2014). Varia História, vol. 31, n. 57, pp. 863-902, 2015.

RANCIÈRE, Jacques. Ódio à Democracia. São Paulo: Boitempo, 2014.

RICOUER, Paul. A Memória, a História, o Esquecimento. Campinas: Editora Unicamp, 2007.

SAFATLE, Vladimir. Bem-vindo ao porão. 19 mai. 2019. Disponível em: https://www1. folha.uol.com.br/colunas/vladimirsafatle/2019/05/bem-vindo-ao-porao.shtml. Acesso em: 1 nov. 2020. 
SPIEGEL, Gabrielle M. Revising the Past/Revisiting the Present: How Change Happens in Historiography. History and Theory, Wesleyan University, vol. 46, pp. 1-19, 2007.

TRILOGIA PÁTRIA EDUCADORA. Disponível em: https://site.brasilparalelo.com. br/series/patria-educadora/. Acesso em: 1 nov. 2020.

TROUILLOT, Michel-Rolph. Silencing the Past: Power and the Production of History. Boston: Beacon Press, 1995.

VALENCIA-GARCÍA, Louie Dean (Ed.). Far-Right Revisionism and the End of History: Alt/Histories. London: Routledge, 2020.

VALIM, Patrícia; AVELAR, Alexandre de Sá. Negacionismo histórico: entre a governamentalidade e a violação dos direitos fundamentais, 3 set. 2020. Disponível em: https://revistacult.uol.com.br/home/negacionismo-historico/. Acesso em: 22 out. 2020.

WHITE, Hayden. Figural Realism: Studies in the Mimesis Effect. Baltimore: The Johns Hopkins University Press, 1999.

WHITE, Hayden. The Fiction of Narrative: essays on history, literature and theory, 1957-2007. Baltimore: The Johns Hopkins University Press, 2010.

WHITE, Hayden. The Practical Past. Evanston: Northwestern University Press, 2014.

\section{NOTAS}

${ }^{1}$ Uma versão preliminar deste texto foi apresentada na mesa-redonda "Os negacionismos e o anticientificismo no Brasil e no mundo", realizada na Fiocruz em junho de 2019. Agradeço aos/às colegas pelas discussões.

${ }^{2}$ Nesse artigo, optei deliberadamente pelo uso do termo "negacionismo" para referir-me ao que considero falsificações do passado ou (im)posturas intelectuais dedicadas ao apagamento obsequioso de determinados acontecimentos de nossas imaginações públicas. Chamá-los de "revisionistas" seria dar-lhes um crédito que não merecem, porque não estão interessados em revisões produtivas e responsáveis de nossas histórias, mas na imposição de falsidades para darem chancela aos projetos de poder da Nova Direita, vitoriosa nas eleições brasileiras de 2018. Para uma excelente análise do fenômeno da revisão na historiografia, assim como para a sua diferenciação dos revisionismos espúrios, ver Spiegel, 2007.

${ }^{3}$ Cf. Câmara dos Deputados..., 2019.

${ }^{4}$ Direção da Biblioteca Nacional.

${ }^{5}$ Cf. O Método Que...

${ }^{6}$ Ver, sobre isso, a reveladora entrevista dada por um de seus criadores a um sítio virtual de extrema-direita (Brasil Paralelo, 2018). 
${ }^{7}$ A leitora e o leitor perceberão que, ao longo deste texto, eu não menciono nominalmente nenhum destes colaboradores. A razão para tanto é porque penso que o significante "Brasil Paralelo" é suficiente para os fins críticos deste ensaio, já que não existem diferenças substanciais nos pontos de vista expressos pelos entrevistados nos vídeos abaixo criticados. De todo modo, no website da empresa há uma lista atualizada de seus apoiadores e colaboradores. Cf. Trilogia Pátria Educadora.

${ }^{8}$ Uso esse termo inspirado nas ponderações de Imre Kertész (2004) sobre certas representações do Holocausto que, num só tempo, negam as amplas consequências ético-políticas desse evento e são "incapazes de compreender a relação orgânica" entre ele e o "nosso deformado modo de vida", retirando-o do "reino da experiência humana". Reduzidas às devidas proporções, esse é o gesto realizado pelas narrativas do Brasil Paralelo sobre a escravidão no Brasil.

${ }^{9}$ Todas as referências a seguir, salvo quando indicadas ao contrário, são do documentário “A Vila Rica | Brasil - A Última Cruzada” (Capítulo 2...).

${ }^{10}$ Sobre essas fórmulas de trivialização, ver Trouillot, 1995, pp. 95-98.

${ }^{11}$ Quando falo em "sujeição à política", quero dizer que a tese final da obra (a de que ditadura foi uma reação ao comunismo, e que a democracia que se seguiu foi a vitória dos derrotados em 1964) ordena toda a narrativa e a "pesquisa" a uma conclusão dada a priori. Nesse caso, o passado é instrumentalizado para a legitimação de uma nova ordenação da pólis (dada com a vitória da Nova Direita em 2018), sem nenhuma outra preocupação conceitual ou cognitiva. O que sobra, enfim, é pura política e, com isso, a história transforma-se em propaganda. Agradeço um/a dos/as revisores/as, que apontou essa questão na sua avaliação do texto.

${ }^{12} \mathrm{Um}$ dos elementos centrais do enredo do filme é a revelação, a partir de fontes recuperadas dos arquivos das antigas forças de segurança da Tchecoslováquia comunista, de que o governo brasileiro estaria "completamente" infiltrado por espiões a serviço delas e da KGB soviética. No entanto, segundo Eduardo Escorel (2019), tais fontes, certamente importantes, deveriam ter sido matizadas por outras ou usadas com cautela, algo que a boa historiografia sempre fez - como, aliás, advertem os próprios pesquisadores que primeiro as sistematizaram. No filme, contudo, elas são transformadas em "prova inegável” de que a administração de Jango estava corrompida pelo bolchevismo e usadas para legitimar o golpe de estado de 1964. Com isso, temos, uma vez mais, uma falsificação deliberada do registro histórico pelos realizadores da obra.

${ }^{13}$ Veja-se, por exemplo, o documento do governo norte-americano que confirma que Ernesto Geisel não só sabia das execuções e torturas, como as autorizou pessoalmente. Cf. 99. Memorandum From..., 1974.

${ }^{14}$ Em relação aos crimes da ditadura, ver o dossiê organizado pela Comissão de Familiares de Mortos e Desaparecidos Políticos, publicado originalmente em 1984 e ampliado em 2009 (Cf. Comissão de Familiares..., 2009). 
${ }^{15}$ O que Ab’Sáber chama de "ficcionalização" eu chamaria, seguindo Fernando Nicolazzi e Caroline Bauer (2016), de "falsificação" da história.

${ }^{16}$ Na primeira parte de uma outra série de vídeos, "O Dia depois da Eleição”, o apreço dos empreendedores do Brasil Paralelo pela última ditadura civil-militar fica ainda mais nítido. Nela, eles elogiam a Constituição de 1967, liberticida e autoritária, por seu papel de "fomentar a liberdade econômica". Cf. O Dia Depois..., 2018.

${ }^{17}$ Até o momento da revisão final deste texto, só "1964, o Brasil entre Armas e Livros" possuía mais de cinco milhões de visualizações no YouTube.

${ }^{18}$ Essa é, evidentemente, uma impressão dada por alguns indícios: em primeiro lugar, o rol de colaboradores, cuja grande maioria é branca, masculina e (ao que tudo indica) heterossexual; em segundo lugar, as escolhas de heróis, os personagens principais de suas narrativas, igualmente brancos e homens, com raras exceções; e, em terceiro lugar, as opiniões mobilizadas pelos colaboradores em outros espaços, geralmente antifeministas, anti-LGBTQ e contrárias às demandas por reconhecimento e reparação feitas, por exemplos, por lideranças indígenas e negras.

${ }^{19}$ Ao fim de "1964, o Brasil entre Armas e Livros", um polemista de extrema-direita afirma categoricamente que a "esquerda" não "possui sentimentos humanos".

Artigo submetido em 3 de novembro de 2020.

Aprovado em 9 de março de 2021.

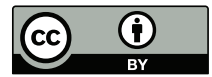

